\title{
Osteoporosis knowledge among female school students in Jordan
}

\author{
L. Abushaikha, ${ }^{1}$ S. Omran ${ }^{1}$ and L. Barrouq ${ }^{1}$
}

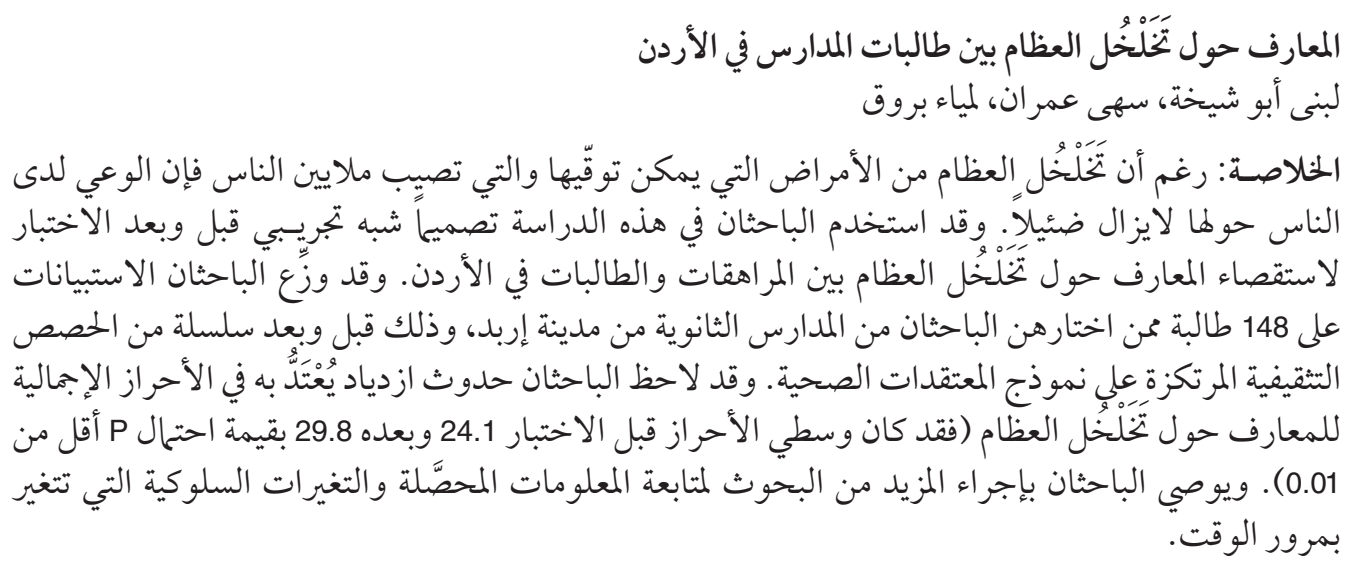

ABSTRACT Although osteoporosis is a preventable disease affecting millions of people, public awareness remains low. This study used a pretest-posttest quasi-experimental design to explore osteoporosis knowledge among adolescent female students in Jordan. A questionnaire was administered to 148 students recruited from a secondary school in the city of Irbid before and after a series of health education sessions based on the health belief model. A significant increase in overall scores for osteoporosis knowledge was seen (mean score pretest $=24.1$ and posttest $=29.8$, $P<0.001$ ). Further research geared toward the follow-up of attained knowledge and behavioural change over time is greatly needed.

\section{Connaissances sur l'ostéoporose chez les jeunes filles scolarisées en Jordanie}

RÉSUMÉ Bien que l'ostéoporose soit une maladie évitable qui touche des millions de personnes, la population y est toujours peu sensibilisée. Cette étude a suivi une structure quasi-expérimentale prétest-post-test pour analyser les connaissances de cette maladie chez des adolescentes scolarisées en Jordanie. Un questionnaire a été remis à 148 élèves recrutées dans un établissement d'enseignement secondaire de la ville d'Irbid avant et après une série de séances d'éducation sanitaire fondées sur le modèle des croyances relatives à la santé. On a observé une augmentation significative des scores généraux en matière de connaissances sur l'ostéoporose (score moyen pré-test $=24,1$ et post-test $=29,8, P<0,001$ ). Une intensification de la recherche axée sur le suivi des connaissances acquises et sur le changement comportemental avec le temps est plus que nécessaire.

${ }^{1}$ Department of Maternal and Child Health, Faculty of Nursing, Jordan University of Science and Technology, Irbid, Jordan (Correspondence to L. Abushaikha: lub2001@just.edu.jo).

Received: 18/09/06; accepted: 24/04/07

المجلة الصحية لشرق المتوسط، منظمة الصحة العالمية، المجلد الخامس عشر، العلد ع، 9 +. 


\section{Introduction}

Osteoporosis is characterized by decreased bone density leading to a higher susceptibility to strains and fractures $[1-10]$. Although it is a preventable disease, osteoporosis affects an estimated 25 million people worldwide, leading to 1 million fractures, 40000 annual deaths and health costs of billions of dollars [4-6]. An estimated 1 in 2 women and 1 in 8 men over the age of 50 years will have osteoporosis-related fractures in their lifetime $[3,6]$.

Public awareness of osteoporosis remains low, especially in less-developed countries. Health education programmes have been shown to be effective in improving knowledge and awareness among the public $[1,5,7-10]$ and in retaining the knowledge over time $[8,9]$. Nonetheless, researchers have emphasized that osteoporosis education programmes seldom change beliefs and behaviours $[1,4,5]$. Schools can be one of the best venues for increasing knowledge of osteoporosis and inducing lasting behavioural change during adolescence, the period of peak bone density [9,11-13].

Jordan is currently in a stage of epidemiological transition, represented by increasing numbers of females entering peak childbearing years, a growing elderly population, the majority of whom are women, and a lack of health care services for postmenopausal women [14]. Studies on osteoporosis in Jordan have been limited, mainly focusing on exploring osteoporosis risk factors and its prevalence in Jordanian society, especially among middle-aged women. The reported prevalence of osteoporosis in Jordan ranges from $13 \%$ to $44 \%[15,16]$; these researchers have recommended increasing public awareness and implementing intensive screening programmes as effective means of preventing and managing osteoporosis in Jordanian society.
Considering the limited studies focusing on osteoporosis in Jordan, the purpose of this study was to assess osteoporosis knowledge among adolescent female Jordanian school students. The study could serve as the basis for developing and implementing future health promotion programmes geared towards Jordanian youth.

\section{Methods}

A pretest-posttest quasi-experimental design was used to assess osteoporosis knowledge among adolescent female school students in Jordan before and after a series of health education sessions. The theoretical basis for the health education programme was the health belief model, which hypothesizes that the perceived threat of a disease (severity and susceptibility) and perceived benefits of the treatment can induce behavioural change $[8,17-19]$.

\section{Sample and setting}

The study was conducted at a major secondary school for girls located in the city of Irbid in the northern part of Jordan. This school has 23 class sections, 727 students and 57 teachers. The school is well-equipped with rooms appropriate for conducting educational sessions for students and with audiovisual aids (e.g. television, video cassette recorder, overhead projector). A convenience sample of 148 female school students in the 11th grade was used.

\section{Data collection}

A 12-item questionnaire was developed for this study after an extensive literature review. The questionnaire had a multiplechoice format in which the student was instructed to choose the correct answer from a group of answers. The questionnaires were scored based on correct answers and

المجلة الصحية لشرق المتوسط، منظمة الصحة العالمية، المجلد الخنامس عشر، العدد ع، 9 +. 
given a score out of 54 in the pre- and posttest. It assessed knowledge of: osteoporosis prevalence and risk factors; manifestations, diagnosis and treatment; and nutritional prevention and calcium-rich foods. Internal consistency reliability of the questionnaire was 0.49 . Content validity was established by a panel of 3 nursing faculty members.

Permission to conduct the study was obtained from the Jordan University of Science and Technology Human Research Committee, the Ministry of Education office in Irbid and the school principal. Consent was obtained from the participants before starting the sessions. Participation in this study was voluntary and the results were reported in aggregate form to avoid personal identification.

After permissions were obtained, the school principal, teachers and researchers collaborated on preparing the sessions. Over a period of 6 weeks in 2002, a researcher (L.B.) gave a series of 6 lectures about osteoporosis. Initial assessment of osteoporosis knowledge was made after students had attended a general osteoporosis lecture. The first 3 lectures represented the pretest component and were followed by 3 posttest lectures that focused on areas of osteoporosis knowledge where students showed weakness, after which students took the knowledge test a second time. Each lecture lasted 45 minutes and the content included manifestations of osteoporosis, risk factors, complications and preventive measures. Each lecture started with a theoretical component that incorporated active interactions with students, while at the end of the session, time was allowed for questions and comments. Osteoporosis pamphlets were distributed to the students at each lecture.

The questionnaire on osteoporosis knowledge was given to the students before the sessions (pretest) and repeated after the intervention on the same students (posttest). The maximum score on the test was 54. These scores were converted to overall percentages, then the percentage of correct answers in the pretest was compared to the percentage of answers in the posttest. $P$-values were calculated for the overall percentage. Then the overall mean score for the pretest was compared to the overall mean score of the posttest.

\section{Results}

The sample consisted of 148 female students, age range $16-18$ years.

Pretest and posttest analysis revealed a significant overall increase in osteoporosis knowledge scores among the students after the health education sessions (mean score pretest $=24.1$; posttest $=29.8, t=9.6, P$ $<0.001$ ) (Table 1).

Significant increases in the percentage of students scoring correct responses were observed for 8 of the 12 knowledge items. There was no change in scores for 4 items, indicating the need for further education and more focus. These items included fracture risk factors, osteoporosis diagnosis, treatment of osteoporosis and fracture pain (Table 2).

\section{Discussion}

The purpose of this study was to explore the extent of osteoporosis knowledge among adolescent female students in Jordan, who represent an understudied target group. A significant increase in overall osteoporosis knowledge was detected among the students after attending health education sessions. This finding is similar to results reported by other studies of osteoporosis education on youth [9-13]. Other researchers too acknowledged that osteoporosis health 


\begin{tabular}{|c|c|c|c|c|c|c|}
\hline \multirow{2}{*}{$\begin{array}{l}\text { Osteoporosis } \\
\text { knowledge item }\end{array}$} & \multicolumn{2}{|c|}{ Pretest score } & \multicolumn{2}{|c|}{ Posttest score } & \multirow[t]{2}{*}{$t$-value } & \multirow[t]{2}{*}{$P$-value } \\
\hline & Mean & SD & Mean & SD & & \\
\hline Prevalence & 5.5 & 2.0 & 7.2 & 2.0 & 7.51 & $<0.001$ \\
\hline Age of onset & 0.8 & 0.4 & 0.8 & 0.4 & 0.61 & 0.543 \\
\hline Fracture risk factors & 1.7 & 0.9 & 1.7 & 0.9 & 0.13 & 0.900 \\
\hline Reasons for fracture & 5.7 & 2.0 & 6.9 & 2.0 & 5.24 & $<0.001$ \\
\hline Fracture pain & 3.9 & 1.1 & 3.9 & 1.3 & 0.00 & 1.000 \\
\hline Fracture and height & 1.6 & 0.7 & 2.0 & 0.9 & 4.04 & $<0.001$ \\
\hline Fracture sites & 2.1 & 1.4 & 3.1 & 1.6 & 5.69 & $<0.001$ \\
\hline Diagnosis & 0.5 & 0.5 & 0.5 & 0.5 & 0.58 & 0.562 \\
\hline Diagnostic tests & 0.4 & 0.5 & 0.8 & 0.4 & 6.61 & $<0.001$ \\
\hline Prevention & 0.5 & 0.5 & 0.9 & 0.3 & 8.14 & $<0.001$ \\
\hline Treatment & 0.9 & 0.3 & 1.0 & 0.2 & 0.97 & 0.332 \\
\hline \multicolumn{7}{|l|}{ Calcium and vitamin D } \\
\hline sources & 0.4 & 0.5 & 0.7 & 0.5 & 5.40 & $<0.001$ \\
\hline All & 24.1 & 5.3 & 29.8 & 5.0 & 9.55 & $<0.001$ \\
\hline
\end{tabular}

$S D=$ standard deviation

education programmes are instrumental in improving and enhancing public knowledge among different age groups $[1,4,5]$. In Jordan, most of the osteoporosis studies so

\begin{tabular}{lcc}
\hline $\begin{array}{l}\text { Table } 2 \text { Percentage of adolescent female } \\
\text { students }(n=148) \\
\text { to each item of osteoporosis knowledge }\end{array}$ \\
$\begin{array}{l}\text { questionnaire before and after health } \\
\text { education sessions }\end{array}$ \\
$\begin{array}{l}\text { Osteoporosis } \\
\text { knowledge item }\end{array}$ & $\begin{array}{c}\text { Pretest } \\
\text { \% correct }\end{array}$ & $\begin{array}{c}\text { Posttest } \\
\% \text { correct }\end{array}$ \\
\hline Prevalence & 55 & 72 \\
Age of onset & 40 & 70 \\
Fracture risk factors & 80 & 80 \\
Reasons for fracture & 50 & 90 \\
Fracture pain & 90 & 90 \\
Fracture and height & 40 & 80 \\
Fracture sites & 21 & 31 \\
Diagnosis & 17 & 17 \\
Diagnostic tests & 57 & 69 \\
Prevention & 16 & 19 \\
Treatment & 39 & 39 \\
Sources of calcium & & \\
and vitamin D & 50 & 90 \\
\hline
\end{tabular}

far have focused on middle-aged women Studies focusing on other age groups such as adolescents are warranted in this area.

Nonetheless, our results also showed that no health education programme is perfect in all aspects. Some areas of osteoporosis knowledge such as fracture risk factors, osteoporosis diagnosis, treatment of osteoporosis and fracture pain did not show significant differences between the pretest and posttest scores, indicating a need to focus on these areas on future osteoporosis education programmes as well as adopting need-focused education programmes. This result differed somewhat from other researchers who reported that responses on all questionnaire items had increased in the posttest $[4,5,9,11]$. They explained their findings as methodological problems related to pretest-posttest designs. Another methodological concern was finding reliable and valid questionnaires to assess osteoporosis knowledge. In our study the 12-item questionnaire had a reliability of 0.49 , which is weak. Reported reliabilities

المجلة الصحية لشرق المتوسط، منظمة الصحة العالمية، المجلد الخامس عشر، العدد ع، 9 + ب 
of the Healthy Bones Knowledge Questionnaire range from $0.51-0.74$, which also indicates fairly low consistency reliability [9]. Thus, finding reliable and valid osteoporosis instruments remains an area of concern for researchers.

In order to meet the challenges and threats of osteoporosis, prevention efforts in Jordan need to be geared toward establishing and sustaining educational programmes for young girls and women. An important step has been the establishment of the Jordanian Osteoporosis Prevention Society in February 1998. The Society is a founding member of the Pan Arab Osteoporosis Society, which was founded in 1997 and is a member of the
International Osteoporosis Foundation [20]. The Jordanian Osteoporosis Prevention Society aims at improving awareness regarding osteoporosis, preventing osteoporosis, enhancing research and helping patients through special programmes [20].

There is a great need for more research with various samples and different age groups when exploring osteoporosis among Jordanian women. The challenge remains in turning knowledge gained from health education into lifelong practices and adopting new health behaviours. Further research geared toward the follow-up of attained knowledge and behavioural change over time is needed.

\section{References}

1. Sedlak CA, Doheny MO, Jones SL. Osteoporosis education programs: changing knowledge and behaviors. Public health nursing, 2000, 17:398-402.

2. Yu S, Huang Y. Knowledge of, attitudes toward, and activity to prevent osteoporosis among middle-aged and elderly women. Journal of nursing research, 2003, 11:65-71.

3. Berarducci A. Osteoporosis education: a health-promotion mandate for nurses. Orthopaedic nursing, 2004, 23:118-20.

4. Ribeiro V, Blakeley J, Laryea M. Women's knowledge and practices regarding the prevention and treatment of osteoporosis. Health care for women international, 2000, 21:347-53.

5. Ribeiro V, Blakely JA. Evaluation of an osteoporosis workshop for women. Public health nursing, 2001, 18:186-93.

6. Whitehead D et al. A preventative health education programme for osteoporosis. Journal of advanced nursing, 2004, 47:15-24.

7. Cindas A, Savas S. What do men who are at risk of osteoporosis know about osteoporosis in developing countries? Scandinavian journal of caring sciences, 2004, 18:188-92.

8. Turner LW et al. Design and implementation of an osteoporosis prevention program using the health belief model. American journal of health studies, 2004, 19:115-21.

9. Brown SJ, Schoenly L. Test of an educational intervention for osteoporosis prevention with US adolescents. Orthopaedic nursing, 2004, 23:245-51.

10. Ziccardi SL, Sedlak CA, Doheny MO. Knowledge and beliefs of osteoporosis in college nursing students. Orthopaedic nursing, 2004, 23:128-33.

11. Harvey C. Osteoporosis prevention teaching in our nation's schools: Options ... how it works. Orthopaedic nursing, 2002, 21:80-1.

12. Rodts MF. NAON intervenes to help our youth. Orthopaedic nursing, 2004, 23:224.

13. Keirle K, Thomas M. The influence of school health education on the knowledge and behaviors of school children towards 
nutrition and health. Research in science and technology education, 2000, 18:173-81.

14. Chowdhury D. Reproductive health needs of menopausal women in Jordan. Amman, Jordan, Princess Basma Women's Resources Center Bulletin, 2000:1-34.

15. Shilbayeh S. Prevalence of osteoporosis and its reproductive risk factors among Jordanian women: a cross-sectional study. Osteoporosis international, 2003, 14:929-40.

16. Al-Qutob RJ et al. The magnitude of osteoporosis in middle-aged women. Saudi medical journal, 2001, 22:1109-17.
17. Wallace LS. Osteoporosis prevention in college women: application of the extended health belief model. American journal of health behaviour, 2002, 26:163-72.

18. Chang S-F et al. Predictors of community women's osteoporosis prevention intention-a pilot study. Journal of nursing research, 2003, 11:231-9.

19. McGinley AM. Health beliefs and women's use of hormone replacement therapy. Holistic nursing practice, 2004, 18:18-25.

20. What is JOHPS? Introduction. Jordanian Osteoporosis Prevention Society [online] (http://www.jops.org/intro.html, accessed 27 November 2008).

\section{Health and development through physical activity and sport} (WHO/MMH/MPH/PAH/O3.2)

The world is witnessing a significant increase of the global burden of non-communicable diseases (MCD). The increasing global epidemic of relates closely to respective changes in lifestyles. The risk factors, including physical inactivity, contribute significantly to the overall burden of MCD worldwide.

Among other benefits, regular physical activity:

- helps prevent osteoporosis, reducing the risk of hip fracture

- reduces the risk of dying from heart disease or stroke

- helps to prevent/reduce hypertension

- helps build and maintain healthy bones, muscles, and joints

- promotes psychological well-being and reduces stress

This document can be downloaded at: http://whqlibdoc.who.int/ hq/2003/WHO_MMH_MPH_PAH_03.2.pdf 